\title{
AN ANALYSIS OF CHILDREN'S ATTITUDES TOWARD OLDER ADULTS
}

\author{
G. Petkova* \\ PU “Paisii Hilendarski”, Plovdiv, Bulgaria
}

\begin{abstract}
ABSTRAKT
This article presents a psychological research, instigated by the latest trend of an increase in the number of ageing population, which has been characteristic for the country over the last decades, and which ranks Bulgaria fifth in Europe. The subjects of the investigation are children aged 10 to 12 . The paper analyses children's attitudes toward older adults. The aim is to trace this relationships.
\end{abstract}

Key words: attitudes, older adults, relations.

\section{Literature Review}

The objective of this literature review is to form a better understanding of the development of children's attitudes toward older people and the processes involved in the development of those attitudes. Laws (1995) suggests that society has transformed biological and chronological age into social and cultural signs. Perceived differences between young and old people are, therefore, not necessarily reducible to biological causes. How a culture views age is often based upon socially/culturally agreed upon standards. How are children's attitudes about and perceptions of older adults formed? The answer to this question is complex.

\section{Socialization}

"The process whereby the child becomes a social being" is perhaps the most comprehensive short definition of "socialization" (Grusec \& Lytton, 1988, p. 161). The word "socialization" implies that the individual lives in a social world, that is, within a group, and group living, by its nature, imposes its own restraints and patterns of living. It is early in childhood that the child most actively and rapidly acquires these patterns of behavior. He/she does so by means of and in context with his interactions with his family. The family, at least in most forms of Western society, is the primary agent of socialization. One may also define socialization as the process by which an

${ }^{*}$ Correspondence to: GALINA PETKOVA, PU "PAISII HILENDARSKI", e-mail: hristova.petkova@abv.bg, tel:0886060877 individual learns the ways of a given society or social group so that he/she may function in it. This includes learning and internalizing appropriate patterns, values, and feelings. Since the socialization process occurs through social relationships, a child cannot learn the ways of the society by being apart from people. The child's family and others, wittingly or unwittingly, teach a child through their guidance, examples, responses, and emotional attachments. Socialization, thus, is a function of social interactions (Grusec \& Lytton, 1988). The socialization process is not adequate by itself in describing the multifaceted phenomenon of human development. The interplay of various environments makes it necessary to view the child in a dynamic ecosystem. For example, underlying the social development of the child is the biological factor. The biological organism requires input from its near environment such as food, warmth, space, and air. It then follows a systematic and orderly pattern in development of neural, muscular, and glandular tissues. No amount of training can enable a person to function in a given way before he is biologically ready. Maturation and socialization are highly interrelated. Jean Piaget (1896), a Swiss psychologist noted for his work with nursery school children, showed that there are distinct lines of development, and quite early in a child's life social factors combine with physiological development to influence the child's ways of thought and perception of the world. The agencies of socialization such as the family, community, school, peer group, and mass communication 
create a flow of informational input and output resulting in mechanisms for interactions between the social as well as the technological and physical environments (Rutter et. al. 1979; Abramovitch \& Grusec, 1978; Abramovitch et. al., 1982; Spigel, 1992). The degree to which a child's ecosystem is open or closed to the family ecosystem depends upon the relationship between the adult and the child. If, for example, the parent's perceptions of elderly people are positive and realistic, then the system will remain open to the child and may affect the child's perceptions. The child may have a more positive and realistic perception of elderly people. If, on the other hand, parents hold negative attitudes concerning the elderly, the family may partially close its boundaries in the area of intergenerational reciprocities as well as in controlling and defining the parameters of the child's ecosystem. This may then allow for a more negative stereotype input. Harris (1995) contends that while negotiating satisfactory relationships with parents and siblings is an important undertaking of early childhood, much of what is learned in the course of it may be of little use outside the home. She explains that outside the home, children may be judged more harshly or less harshly, and they must use different strategies to achieve their goals. According to group socialization, which Harris espouses, children learn how to behave outside the home by becoming members of a social group. In today's societies, socialization gets its start in nursery school or day-care centers, gathers momentum in the sameage, same-sex peer groups of school-age children, and approaches a peak in the mixed-sex crowds of adolescence. It is within these groups, then, that the psychological characteristics with which a child is born become permanently modified by the environment. Two processes, assimilation and differentiation, are responsible for the modifications. Assimilation transmits cultural norms, smoothes off rough edges of the personality, and makes children more like their peers. Differentiation exaggerates individual differences and increases variability. Which of these processes will dominate at a given moment depends on contextual variables that cause social categories to become more or less salient.

\section{Attitudes toward Older People}

Attitudes will be defined as "the amount of affect for or against something or a person's favorable or unfavorable evaluation of an object"(Fishbein and Ajzen, 1975). Researchers studying attitudes and intergenerational issues have related the development of negative attitudes regarding older people to the artificial age segregation that currently exists in our culture (Carstensen, Mason, \& Caldwell, 1982; Murphy-Russell, Die, \& Walker, 1986; Seefeldt, 1987). Studies examining younger people's attitudes regarding older people, however, have resulted in contradictory findings (Crockett \& Hummert, 1987; Lutsky, 1981).

\section{Negative Attitude Findings}

A significant number of attitude investigations have found that individuals of different ages hold mixed to negative attitudes toward older people (Bennett \& Eckman; Burke, 1982; Caspi, 1984; Hummert, 1990; Seefeldt, 1987; Seefeldt. Jantz, Galper, \& Serock, 1977). Negative attitudes toward older people have been found in the media (Atchley, 1988) and among nursing students (Campbell, 1971), medical doctors (Lieff, 1982), college students (Levin, 1988; Naus, 1973), adolescents (Doka, 1986), and adults (Locke-Connor \& Walsh, 1980; Isaacs \& Bearison, 1986; Page, Olivas, Driver, \& Driver, 1981). The seminal research on younger people's attitudes toward older people was conducted by Hickey et. al. (1968). In this study, 208 third grade students from 4 schools varying in socioeconomic status wrote a short paper describing an "old person like your grandparents". The researchers found that children as young as 8 years old held primarily negative attitudes toward older persons. Page et. al. (1981) interviewed 144 children about their attitudes toward older people and the aging process. The authors found that younger people characterized older people based on their physical characteristics (e.g. wrinkles, false teeth, grey hair), and that three-quarters of the young people expressed negative feelings about their own aging. Seefeldt et. al. (1977) elicited children's attitudes toward older people by using pencil drawings of people at different ages. The authors found that a majority of the younger people held negative attitudes toward their own aging. Crockett and Hummert (1987) reviewed the literature examining different age groups' attitudes toward older people and found that individuals hold a variety of negative, positive, and mixed attitudes regarding older people. Older people, however, were consistently viewed more negatively when compared to younger people, and negatively biased beliefs about old age still outnumbered positive ones.

\section{Mixed to Positive Attitude Findings}

The widely reported finding that individuals from different age groups hold negative attitudes toward older people has been challenged in reviews of the attitude literature (Crockett \& Hummert, 1987; Greene, 1981; 
Kogan, 1979; Lutsky, 1981). Similarly, several investigations have concluded that younger persons actually hold mixed to positive attitudes toward older people (Braithwaite, 1986; Burke, 1982; Fillmer, 1984; Harris, Page, \& Begay, 1988; Kite \& Johnson, 1988; Marks, Newman, \& Onawola, 1985). Crockett and Hummert (1987) and Lutsky (1981) reviewed the literature examining different age groups' attitudes toward older people and found that individuals hold a variety of negative, positive, and mixed attitudes regarding older people. Crockett and Hummert concluded that the overall ratings of older people in the majority of studies were actually slightly positive. Older people, however, were consistently viewed more negatively when compared with younger people, and negatively biased beliefs about old age still outnumbered positive ones. Kite and Johnson (1988) conducted a meta-analysis of the literature and found an overall negative bias toward older people, but only when they were compared with younger people. The authors maintained that negative attitudes toward old people may be a function of poorly worded instruments which cue subjects to evaluate older people based on their physical appearance and competence rather than on their personality traits. The disparity in findings in the attitude literature reflects a lack of methodological rigor and conceptual clarity. First, wide variability exists in the way the attitude construct is operationalized and measured (Crockett \& Hummert, 1987; Lutsky, 1981; Slotterback \& Saarnio, 1996). The attitude construct has been used interchangeably with such terms as "perceptions" (Aday, Sims, \& Evans, 1991; Carstensen, Mason, \& Caldwell, 1982), "awareness", "intentions", and "beliefs" (Allred \& Dobson, 1987), "stereotype" and "ageism" (Butler, 1969), and "prosocial behaviors" (Lambert, Dellman-Jenkins, \& Fruit, 1990). Secondly, there is wide variation in the ways in which older persons are characterized in the various attitude inventories (Slotterback \& Saarnio, 1996). For example, some studies have used photographs of unfamiliar older men and women. Other studies have younger people rate only female older people. Third, a positive or negative attitude evaluation of older persons often depends on whether or not they are being compared with younger persons on specific traits (Brubaker \& Powers, 1976; Crockett \& Hummert, 1987; Green, 1981). Finally, several studies have utilized measures whose psychometric properties have not been thoroughly tested.

\section{Knowledge about Older Adults}

The information model focuses on the information available to members of one group about the other group (Brislin, 1986; Triandis, 1975). The main assumption of this model is that ignorance and lack of information comprise the basis for the development of prejudice, stereotypes, and consequent tension between groups. Members of one group, therefore, must understand the cultural characteristics of the other group before being able to understand and positively evaluate individual members of this group. Stephan and Stephan (1984) found that contact between Anglo and Chicano students, along with acquisition of new information about the Chicano culture, led to more positive attitudes toward Chicano classmates. Gardiner (1972) found that learning about the outgroup can improve intergroup attitudes and stereotypes. Factual information provided about ingroups is more extensively recalled than similar information about outgroups (Park \& Rothbart, 1982). The reason is that people tend to encode information about ingroups using specific, highly differentiated categories, whereas they encode outgroup information using global categories. This finding is consistent with studies of eyewitness identification showing that blacks and whites have more difficulty identifying outgroup members they have previously seen than they do identifying ingroup members (Brigham \& Malpass, 1985). Distinctive pairings of groups with traits may also be highly memorable (Hamilton, Dugan, \& Trolier, 1985). Rothbart et. al. (1978) found that when a distinctive outgroup engages in negative behavior, this association is likely to be recalled as having occurred frequently. For instance, it has been found that the frequency with which negative behaviors are presented as having been performed by a minority group is overestimated (Hamilton \& Gifford, 1976; McArthur \& Friedman, 1980). Evaluations of the distinctive group in the Hamilton and Gifford (1976) study were found to be correspondingly negative. Such overestimates can impede changes in stereotypes and attitudes to the extent that outgroup members engage in negative behaviors. They can, however, facilitate changes in stereotypes and attitudes if distinctive outgroup members engage in highly positive behaviors. There is a paucity of information in the literature regarding children's knowledge of older adults. Holtzman and Beck (1979) report that more knowledge about aging is associated with more positive attitudes toward the aged. Palmore (1980) found that those people with higher educational levels had greater knowledge about older adults. He also found that with 
increasing age, people had greater knowledge about older adults.

\section{Views of Aging}

Satore (1976) maintains that aging is not a topic which is discussed in most classrooms. Frymier (1979) surveyed elementary schools and found almost threequarters of them provided insufficient education about the aging process. Hickey et. al. (1968) found that children as young as eight years have already formed concepts about what old age is. Children as young as three years have been found to internalize negative attitudes regarding the aging process (Hickey et. al., 1968; Kastenbaum \& Durkee, 1964; Seefeldt, 1987; Treybig, 1974). Page et. al. (1981) interviewed 144 children about their attitudes toward older people and the aging process, and found that over two-thirds of the children expressed negative feelings about their own aging. Seefeldt et. al. (1977) found that by the third and fourth grade, a majority of the young people he investigated were able to comprehend the concept of "old", and they held negative attitudes toward their own aging and older people. Marks et. al. (1985) investigated 256 culturally diverse children and found that though the children displayed positive attitudes toward older people, they held negative views of the aging process. Newman et. al. (1997) investigated children's views of aging in fifth-grade students and found that they seemed to understand the complexity of the aging process and the feelings that accompany the unpleasant conditions associated with aging. The children in this study did not view the aging process as negative, however, when they were asked how it would feel to be old, almost half of them expressed negative impressions of some conditions they related to being old. McTavish (1971) argues that children fear growing old because of their misconception that aging is bad. Neugarten (1976) maintains that negative views of aging trigger a variety of concerns including a fear of one's own aging and an increased tendency to avoid interactions with older persons. Beliefs about aging have been found to play an important role in determining the extent of memory loss experienced by older people (Levy \& Langer, 1994). These negative beliefs have also been found to influence the organization and recall of information in older people (Davidson, Cameron, \& Jergovic, 1995). Levy and Langer suggest that negative views about memory loss in the aged can influence an individual's cognitions and lead to a self-fulfilling prophecy (Ryan, 1992). Previous studies (Langer, Perlmuter, Chanowitz, \& Rubin,
1988; Rodin \& Langer, 1980) suggest that early exposure to negative concepts and images in literature and the media regarding older people can influence an individual's eventual level of activity and alertness in old age. The potential consequences of negative views of aging can, therefore, have deleterious effects on the physical and psychological welfare of older people.

\section{Empathy}

The concept of empathy means different things to different people. The central issue in the conceptual debate about empathy has been the extent to which empathy encompasses an affective, as well as a cognitive component. Some researchers (Borke, 1973; Buckley, Siegel, \& Ness, 1979) have defined empathy as the cognitive ability to recognize and understand the thoughts, perspectives, and feelings of another individual. Other researchers (Batson \& Coke, 1981; Feshbach, 1978; Hoffman, 1982; Mehrabian \& Epstein, 1972) have defined empathy as the vicarious experiencing of an emotion that is congruent with, but not necessarily identical to, the emotion of another individual. Feshbach (1978) developed a threecomponent model in which an empathic response requires (1) the ability to discriminate and identify the emotional states of another, (2) the capacity to take the perspective or role of the other, and (3) the evocation of a shared affective response. Since the sharing of another's emotion can result from either direct contact with the affective cues transmitted by the other or from one's knowledge of another's state, the role of cognition in one's empathic arousal is expected to vary considerably from situation to situation. Hoffman (1981) attempts to explain how cognitive and affective factors play changing and interactive roles in the child's social and moral development. According to Hoffman, the child's emerging capacity to understand the distinction between self and other and the growing awareness that other individuals have internal states and feelings independent from one's own lay the foundation for higher levels of empathic responding. The circumstances that will elicit empathic emotional arousal are believed to change and broaden with the child's increasing experiences and cognitive growth. Freeman (1984) found in a study of preschoolers that those who scored high on affective dimensions of empathy also scored high on cognitive dimensions or empathy. This would support the theoretical statements of both Feshbach and Hoffman. For the present study, empathy will be defined as a vicarious emotional response to the perceived emotional experiences of others 
(Bryant, 1982). Another issue with regard to empathy is how to distinguish between empathy and sympathy. Sympathy may be defined as "feeling for" someone, and it often involves feelings of concern, although the conscious cognitive realization that one is concerned about another's welfare is an outcome rather than a part of sympathizing (Wispe, 1986). Often sympathy is the consequence of empathizing, although it may be possible for sympathy to result from processes such as cognitive perspective taking. Whether or not empathy always mediates sympathy is not known. To contrast this view, Goldstein and Michaels (1985) have stated that "the sympathizer, in contrast to the empathizer, is more preoccupied with his/her own feelings in response to the other and thus is less able to respond to, for, or with the other in a manner sensitive to the other person's actual ongoing emotional world and context". In this view, sympathy would involve heightened attention to one's own feelings and the assumed similarity between one's own and another's feelings.

\section{Development of Empathy}

As Hoffman's (1982) theory suggests, there does seem to be some developmental consistency among children, at least early on, in their emotional sensitivity and responsiveness to the needs of others. For example, whereas 1- year-old children often respond to another's distress by orienting to the other, showing distress, and perhaps seeking out their own caretaker, the 2-year-old is much more likely to attempt to intervene effectively on behalf of the victim (RadkeYarrow \& Zahn-Waxler, 1984). Older children have been found to be more likely than their younger counterparts to respond to abstract kinds of distress and subtle cues from others (Radke-Yarrow, Zahn-Waxler, \& Chapman, 1983). Adams et. al. (1993) found a clear developmental progression in preschool children's ability to correctly identify other people's feelings. In addition, they found that girls were more efficient in identifying others' emotions than boys at three years of age, but by age five, boys scored higher on the empathy measure. Zahn-Waxler \& Radke-Yarrow (1982) have reported stable and patterned individual differences in empathic responses among 1- and 2-year-olds as well as individual continuity to age 7 in the child's intensity, complexity, and mode of response to others' emotions. About two-thirds of the children were reported to show a pattern of responding at 7 years of age that was similar to the pattern displayed at 2 years of age. During the first week of life, infants have been found to show distress and cry in response to the sound of another infant's cry (Martin \& Clark, 1982). Interestingly, no such response was made to a computer-simulated sound of equal intensity. Hoffman (1977) suggests that this affective orientation to other infants may represent a "constitutionally based, early precursor of empathy". This may too suggest that humans have an inherent capacity to respond to obvious distress cues in others (Barnett, 1987). Early socialization experiences may influence whether this capacity is suppressed or flourishes during childhood. One suspected early antecedent of empathy concerns the intense affective relationship between the caretaker and the infant. Mussen \& EisenbergBerg (1977) concluded that strong early attachment appears to be a major antecedent of early interest in others and the latter may be a necessary precondition for the development of empathy. Waters et. al (1979) found that children who had a more secure attachment to their mothers at 15 months of age were rated as more responsive to peers' distress in preschool at 3 _ years of age than were children who had been identified as having an anxious attachment to their mothers. There are undoubtedly numerous factors that influence the extent to which a particular child is securely attached to his/her parents. Some of these factors, such as the degree of parental responsiveness to the child's cry and other distress expressions, may have a predominate affective component and be highly relevant to the development of empathy (Barnett, 1987). A common ingredient in a secure early attachment is an abundance of love and nurturance. Not surprisingly, it has been suggested that parental affection, by satisfying the child's own emotional needs, also plays an important role in the development of empathy (Hoffman, 1982). In a study by Barnett et. al. (1980) it was found that highly empathic undergraduates characterized their parents as having been more affectionate with them during childhood than did relatively less empathic undergraduates. There is evidence that modeling and identification processes are major determinants of the acquisition, expression, and developments of prosocial behaviors in children. The availability of empathic models, therefore, may play an important role in the development of empathy (Barnett, 1987). Zahn-Waxler et. al. (1979) found that children of mothers who displayed empathic handling of their toddlers' needs and distress were more emotionally responsive and helpful to persons in distress than were children of less empathic mothers. Although parents are especially important models in their child's social emotional development, the 
child's inclination to empathize may also be enhance by exposure to and interaction with other sensitive and caring models, such as a teacher, sibling, or playmate. In addition to the potential influences of various "live" models, children have been found to emulate television characters who display prosocial actions such as offering sympathy and assistance to needy others (Rushton, 1981). Children who are encouraged to feel good about themselves may be more inclined to empathize with others than children who are preoccupied with personal inadequacies and other concerns about the self. Strayer (1980) found empathy in 6- year-old children to be associated with a positive selfconcept. Strayer (1980) found that children who ranked high on displays of happy emotions (possibly reflecting self-contentment) were also ranked high on empathic behavior toward peers. In contrast, children who were ranked high on displays of sad emotions were ranked low on empathy toward peers.

\section{Empathy and Attitudes}

Empathy has been found to be positively related to prosocial behavior and negatively related to aggression ( Eisenberg \& Fabes, 1990). Batson (1997) found that empathy for a stigmatized outgroup member can improve attitudes toward the whole outgroup. A positive relationship has been documented between empathy and acceptance of individual differences (Bryant, 1982). The more empathic the individual, the more likely will be the sharing of feelings with a wide range of individuals and, thereby, the more accepting of individuals in general, including individuals from groups that are subject to generally negative evaluations. Empathy has been found to increase valuing the welfare of the person for who empathy is felt and, moreover, this valuing has been found to endure after the resultant empathic feelings are gone (Batson, Turk, Shaw, \& Klein, 1995). Schwalbach and Kiernan (2002) found that as empathy increased in children who were participants in an intergenerational program, the children's attitudes toward the older people in the program became more positive. Bagshaw and Adams (1985) studied empathy of nursing home nurses and their attitudes toward their elderly residents. She found that higher levels of empathy among the nurses correlated positively with more positive attitudes toward the elderly residents.

\section{DISCUSSION}

\section{Summary of Findings}

In this study, children were found to have fairly positive attitudes toward older adults. This finding is in opposition to some of the earlier research on children's attitudes toward older people (Page et. al., 1981; Hickey et. al., 1968; Seefeldt et. al., 1977), but it is congruent with other earlier research (Braithwaite, 1986; Burke, 1982; Fillmer, 1984; Harris et. al., 1988: Marks et. al, 1985), as well as with more current research (Newman et. al., 1997; Meshel, 1997). Children's views of aging were found to be midway between positive and negative. This finding is in opposition to some of the earlier research (Hickey et. al., 1968; Kastenbaum \& Durkee, 1964; Seefeldt, 1987; Treybig, 1974), but it is congruent with some of the more current research (Newman et. al., 1997; Meshel, 1997). Children were found to have moderate knowledge about older people. This finding is consistent with prior literature (Haught et. al., 1999). Moreover, children were found to have moderate empathy, which is consistent with the prior literature (Bryant, 1982). That the children in the present study were found to have more positive attitudes toward older adults and more positive views of aging than were reported in earlier studies may have to do with sample bias. The participation rate for the present study was $71 \%$. It is, therefore, possible that the children who chose to participate in the study had higher attitudes toward older adults and more positive views of aging than those who chose not to participate. Another explanation for the more positive findings in this study compared to earlier studies is that there may be cohort differences. The earlier studies were conducted in the 60 's, 70 's, and 80 's, and a number of changes have occurred in our society over the decades since those earlier studies were conducted. Over past decades, technological developments have increased the possibility of building and maintaining relationships in spite of geographic distance. Telephones and computers mean that people are able to communicate and visit regularly, and at a lower cost than in the past, even if they live far from each other (Ward, 1997). In addition, changes have occurred in longevity and retirement patterns. With improved health care and medical treatments of disease, adults are experiencing longer life spans, and the United States is becoming a society of older people (Aday et. al., 1996). With their overall better health, they are remaining active. With regard to retirement patterns, in 1950, a 20-year-old man could anticipate spending 7.5 years in retirement. By 1980, a 20-year-old man could anticipate spending 15 years in retirement (Caplow et. al., 1991). This situation exists still today. Though the trend today is toward earlier retirement, the numbers of people working in parttime positions after the age of 65 has 
increased for both men and women. Given these current situations, the children in this study have had the opportunity to see older adults as more active and more participatory in society than the children in the earlier studies. Finally, the effect of the media (e.g., television, books, periodicals) can not be ignored. The growing affluence of older adults began to draw media and marketing interest in the 1980's. By 1990, advertising geared toward older adults, including ads that featured persons who were clearly aging, was becoming more common. In addition, there have been shifts in portrayal of older adults in children's books. Dellman-Jenkins and Yang (1997) performed an analysis of 95 children's books published between 1972 and 1995 . They found that books published between 1984 and 1995 had significantly more positive portrayals of older adult characters than books published between 1972 and 1983. They also found that in the more recent set of books, older adult characters were more often described as "right", "wonderful", "good", "caring", or "happy" than those in the older set of books. Children who lived closer to their grandparents also had more frequent contact with their grandparents.

This study found that the most salient predictor of children's attitudes toward older adults is knowledge about older adults. This finding is consistent with research by Murphy-Russell, Die, and Walker (1986). Though salience of knowledge in predicting children's attitudes toward older people has not been represented in the literature, there is support for the potency of knowledge as it is related to attitudes, particularly as it is related to attitude change (Seefeldt, 1982; Doka, 1985/1986; Aday \& Campbell, 1995; Meshel, 1997).

That empathy was not found to be a more potent predictor of attitudes may have to do with the fact that the empathy measure assessed general empathy rather than empathy toward a specific target; in this case, older adults. Bryant (1982) argued on the basis of prior research that the more empathic the individual, the more accepting of other individuals, including those from groups subject to negative evaluations. Even in light of this, the general empathy measure used may not have been sufficient to predict attitudes toward a specific target. Possibly an empathy measure that targeted older adults specifically would have yielded different results.

This study may provide the background for the design of intergenerational programs for the purpose of attitude change toward older adults. Intergenerational programs may be examined to assess changes in scores on measures of the predictor variables and attitudes before and after the involvement of younger and older people. The predictor variables may also be manipulated and the effect of the manipulation assessed. This would provide a real-life assessment of the actual salience of the predictor variables as they are related to attitudes. Information from such studies may also be used to support the provision of intergenerational projects in schools, or at the very least, the inclusion of older volunteers in schools.

\section{REFERENCES}

1. Ajzen, I. \& Fishbein, M. (1980). Understanding Attitudes and Predicting Social Behavior. Englewood Cliffs, NJ: Prentice-Hall.

2. Ajzen, I. (1985). Attitude structure and behavior. In A.R. Pratkanis, S.J. Breckler, \& A.G. Greenwald (Eds.). Attitude Structure and Function (pp.241-274). Hillsdale, NJ: Lawrence Erlbaum Associates.

3. Barnett, M.A. (1987). Empathy and related responses in children. In N. Eisenberg \& Strayer, J. (Eds.), Empathy and Its Development. New York: Cambridge University Press.

4. Batson, C.D., Turk, C.L., Shaw, L.L., \& Klein, T.R. (1995). Information function of empathic emotion: Learning that we value the other's welfare. Journal of Personality and Social Psychology, 68, 1042-1054.

5. Bryant, B. K. (1982). An index of empathy for children and adolescents. Child Development, 53, 413-425. 141

6. Bohner, G .(2002). Attitudes and Attitude Change: Social Psychology. PublisherPsychology Press.

7. Breckler, S. J., \& Wiggins, E. C. (1992). On defining attitude and attitude theory: Once more with feeling. In A. R. Pratkanis, S. J. Breckler, \& A. C. Greenwald (Eds.), Attitude structure and function. Hillsdale, NJ: Erlbaum. pp. 407-427.

8. Bless, H. 2004. Social Cognition: How Individuals Construct Reality:Social Psychology. Publisher-Psychology Press.

9. Eisenberg, N. \& Fabes, R. (1990). Empathy: Conceptualization, assessment, and relation to prosocial behavior. Motivation and Emotion, 14, 131-149

10.Marks, R., Newman, S., Onawola, R. (1985). Latency-aged children's view ofaging. Educational Gerontology, 11, 8999.

11.Carstensen, L., Mason, S., \& Caldwell, E. (1982). Children's attitudes toward the elderly: An intergenerational technique for 
change. Educational Gerontology, 8, 291301.

12.Forgas, J., Joel Cooper, J., \& Crano, D. ( 2010). The Psychology of Attitudes and Attitude Change, . Routledge.

13.Harris, D. \& Changas, P. (1994). Revision of Palmore's second facts on aging quiz from true-false to a multiple choice format. Educational Gerontology, 20, 741-754.

14.Palmore, E.B. (1977). Facts on aging: a short quiz. The Gerontologist, 17, 315- 320.

15.Palmore, E.B. (1980). The facts on aging quiz: A review of findings. The Gerontologist, Vol. 20 (6), 669-679.

16.Ma, K. H. \& Leung, C. M.(1991). Altruistic Orientation in Children : Construction and Validation of the Child Altruism Inventory.
The Chinese University of Hong Kong, Hong Kong.

17.Seefeldt, C., Jantz, R., Galper, A., Serock, K. (1977). Children's attitudes toward the elderly: educational implications. Educational Gerontology, Vol. 3, 301-310.

18.Kogan, N. (1961). Attitudes toward old people: The development of a scale and an examination of correlates. Journal of Abnormal and Social Psychology, 62, 4454.

19.Zahn-Waxler, C. \& Radke-Yarrow, M. (1982). The development of altruism: Alternative research strategies. In $\mathrm{N}$. Eisenberg (Ed.), The Development of Prosocial Behavior. New York: Academic Press. 